\title{
OS EFEITOS DA MIMESE: exame do sentido da festa popular em Rousseau e da transmissão radiofônica em Walter Benjamin
}

\author{
THE EFFECTS OF MIMESE: examination of the meaning of popular festival in Rous- \\ seau and radio broadcast in Walter Benjamin
}

LOS EFECTOS DE LA MIMESE: examen del sentido de la fiesta popular en Rousseau y de la transmisión radiofónica en Walter Benjamin.

Sônia Campaner Miguel Ferrari Professora Doutora do Departamento de Filosofia da PUC-SP. soniacamp@pucsp.br

\begin{abstract}
RESUMO: A discussão sobre o teatro, a festa popular e mesmo a transmissão radiofônica insere-se na reflexão mais geral sobre os efeitos da mimese. Para Rousseau o teatro não ensina o homem a ser virtuoso, mas curiosamente pode reforçar seus vícios, ao espelhá-los. Ao delimitar os efeitos gerais do teatro Rousseau reafirma sua descrença em relação à função civilizatória do teatro. Interessante notar que os efeitos do teatro para Rousseau são apenas os negativos - imitação das ações viciosas. Se o teatro representa a virtude, sua principal consequência será a de "reduzir a alguns sentimentos passageiros, estéreis, e sem efeito, todos os deveres do homem, em nos fazer aplaudir a nossa coragem, louvando a dos outros, a nossa humanidade, lamentando os males que poderíamos curar, nossa caridade dizendo ao pobre: Deus te proteja" (Rousseau, Carta a d'Alembert, 1993:47). Mas Rousseau não rejeita o teatro, e sim apresenta as qualidades do teatro conveniente à república. A principal característica desse espetáculo é a não separação entre espectador e espetáculo. Propõe em lugar desse espetáculo a festa cívica, caracterizada pela "reciprocidade" das vozes que leva a uma superação do isolamento. Pretendemos assim fazer um estudo comparativo entre essa proposta e a das peças radiofônicas de Benjamin, com as quais o autor apresenta uma nova popularidade que é para ele uma posição fundamental em relação aos novos meios de comunicação. A popularização não se legitima por meio da mera simplificação, mas da sua ação pragmática.
\end{abstract}

PALAVRAS-CHAVE: Mimese. Espetáculo. Festa popular. Meios de comunicação. Público.

ABSTRACT: The discussion about the theater, the popular party and even the radio broadcast is part of the more general reflection on the effects of mimesis. For Rousseau, the theater does not teach man to be virtuous, but curiously, can it strength their addictions, reflecting them. In defining the overall effects of the theater Rousseau reaffirms his disbelief regarding its civilizing function. It is interesting that the effects of theater to Rousseau are only negative - imitation of vicious actions. If the theater represents virtue, its main effect is to "reduce to some elusive feelings, sterile and void, all the duties of man, in making us applaud our courage, praising of other's, our humanity, regretting the evils that we could heal, or our charity when we say to the poor: God protect you "(Rousseau, Letter to D'Alembert, 1993: 47). Rousseau does not reject the theater, but presents the qualities of convenient theater in the republic. The main feature of this spectacle is the inseparability between spectator and spectacle. He proposes instead this spectacle the civic party characterized by "reciprocity" of the voices that leads to overcome isolation. We intend to make a comparative study between this proposal and Benjamin's radio plays, with which the author presents a new popularity that is for him a key position in relation to new media. The popularization does not legitimate itself through simplification, but by its pragmatic action.

KEYWORDS: Mimesis. Entertainment. Popular party. Media. Public.

Artigo recebido em setembro de 2015

Aprovado em novembro de 2015

Cad. Pes., São Luís, v. 22, n. Especial, set./dez. 2015 
RESUMEN: La discusión sobre el teatro, la fiesta popular y mismo la transmisión radiofónica se incluye en la reflexión más general sobre los efectos de la mimese. Para Rousseau el teatro no enseña al hombre a ser virtuoso, pero curiosamente puede fortalecer sus vicios, reflejándolos. En la definición de los efectos generales del teatro Rousseau reafirma su incredulidad en relación a la función civilizadora del teatro. Interesante mirar que los efectos del teatro para Rousseau son sólo negativos - imitación de las acciones viciosas. Si el teatro representa la virtud, su principal consecuencia es de "reducir a algunos sentimientos pasajeros, estériles y sin efectos, todos los deberes del hombre, en hacernos aplaudir nuestra coraje, alabando a dos otros, la nuestra humanidad, lamentando los males que podrían curarse, nuestra caridad diciendo a lo podrido: Dios te proteja" (Rousseau, Carta a D'Alembert, 1993: 47). Pero Rousseau no rechaza el teatro, y sí presenta las cualidades de teatro convenientes a la república. La característica principal de este espectáculo es la no separación entre el espectador y el espectáculo. Se propone aquí en vez de este espectáculo la fiesta cívica, caracterizada por la "reciprocidad" de las voces que lleva a una superación del aislamiento. Pretendemos así hacer un estudio comparativo entre las propuestas y a las partes radiofónicas de Benjamin, con las cuales el autor presenta una nueva popularidad que es para él una posición fundamental en relación a los nuevos medios de comunicación. La popularización no se legitima por medio de la mera simplificación, sino por su acción pragmática.

PALABRAS CLAVE: Mimese. Entretenimiento. Fiesta Popular. Medios de comunicación Público. 
Pode parecer ousadia aproximar pensadores tão distantes no tempo, como Rousseau e Benjamin. No entanto o tema propicia essa aproximação apesar das diferenças de tom na obra dos autores, diferenças estas, próprias dos problemas da época em que ambos vivem.

A discussão sobre o teatro, a festa popular e a transmissão radiofônica insere-se na reflexão mais geral sobre os efeitos da mimese. Rousseau (1993) está claramente preocupado com esses efeitos, ao afirmar que o teatro não ensina o homem a ser virtuoso, mas que pode, ao contrário, alimentar seus vícios ao espelhá-los. Apesar de apontar seus efeitos nocivos Rousseau não rejeita o teatro, mas apresenta as características teatrais convenientes à República. É nesse ponto que podemos aproximar os dois autores, para posteriormente distanciá-los, pois para o filósofo genebrino a principal característica desse espetáculo é a não separação entre o espectador e a encenação.

Em lugar então, do que chamamos espetáculo, em que essa separação parece ser inevitável, Rousseau propõe a festa cívica caracterizada pela reciprocidade das vozes que leva a uma superação do solipsismo e do isolamento ${ }^{1}$. Benjamin, por outro lado, com os olhos voltados para o público - para o seu lugar nas encenações, sejam elas do teatro, cinema ou rádio - pensa não em termos de uma atividade que faça com que o público deixe de sê-lo (em direção oposta à mimese), mas em uma forma de encenação na qual tal público possa refletir sobre si mesmo, muito próximo assim de Brecht (BENJAMIN, 1994).

A discussão sobre a mimese é marcada desde Platão e Aristóteles ${ }^{2}$, pelo exame de sua função educativa, e nos autores aqui em destaque o mesmo se dá. A questão está em saber como essa função pode ser desempenhada e como ela é pensada: há uma mensagem determinada a ser transmitida - como em Platão - ou o aprendizado se dá de forma indireta, como em Aristóteles.

Diderot em sua época trava uma batalha com o objetivo de, ao questionar as regras clássicas de composição teatral, colocar no palco a "realidade" de modo que os cidadãos possam, diante da representação de situações semelhantes àquelas vividas por eles, refletir sobre si mesmos. E o que se entende por realidade não são necessariamente fatos, mas também, o modo de lidar com os sentimentos. Esta é uma das questões que movem o genebrino na discussão sobre a função do teatro.

Vamos apresentar alguns argumentos de Rousseau já bastante conhecidos extraídos da Carta a D'Alembert (ROUSSEAU, 1993), texto escrito por Rousseau em 1758 em resposta ao Artigo Genebra, de D' Alembert publicado na Enciclopedia. Neste artigo o enciclopedista elogia a constituição moral e política da cidade natal de Rousseau e propõe que nela se estabeleça 0 teatro de comédia, ao que Rousseau se opõe de maneira veemente.

Nesse texto Rousseau analisa o teatro sob o ponto de vista das implicações morais que este ocasiona para a vida prática da sociedade; e sob o ponto de vista do conteúdo representado. Consequentemente, a crítica presente nesse texto manifesta-se sob dois aspectos fundamentais: uma concepção estética original que caminha na margem oposta aos ideais artísticos, fundamentados no louvor ao progresso proferido pela maioria dos representantes do lluminismo; e a impossibilidade de separação entre apreciação estética e função social do espetáculo artístico, chamando a atenção para a sua dimensão política do espetáculo artístico.

\footnotetext{
${ }^{1}$ Podemos tanto pensar em como Rousseau vê a importância da arte como forma de instaurar um debate que retira as pessoas da opinião pessoal e as coloca na relação com os outros sujeitos que contribuem para a formação da imagem do mundo, como também inserir esta discussão numa teoria do conhecimento que se opõe ao isolamento da "coisa pensante" de maneira distinta de como o faz Descartes. Ali o isolamento do sujeito é quebrado pela existência de Deus, em Rousseau o isolamento é superado pelas relações dos homens com outros seus concidadãos.

${ }^{2}$ Cf. Platão, República, Livros II, III e X; Aristóteles, Poética.
} 
Era comum entre os iluministas a ideia de que o acesso aos espetáculos produziria o refinamento dos modos e do gosto, elevando a alma acima de seu estado de natureza, marcado por certa rusticidade e pela busca do necessário para a autopteservação ${ }^{3}$. A partir desse ponto de vista, os espetáculos deixam de se inscrever em uma área puramente estética para perfazer caminhos que interferem na conduta moral da população. Os espetáculos - e o teatro, portanto - passam a carregar uma função pedagógica que reflete a preocupação iluminista em instruir camadas da população que até então haviam sido negligenciadas em suas necessidades educativas.

Nessa perspectiva, a popularização dos espetáculos é uma consequência que envolve diretamente os hábitos dos espectadores. Na perspectiva iluminista, a popularização das várias formas de arte é vista de uma maneira positiva e os espetáculos, em particular o teatro, passam a ter a dupla função de divertir e instruir.

Para Rousseau o espetáculo teatral não é bom nem mau em si mesmo. Essa pergunta - o teatro é bom ou mau em si mesmo? - é para ele uma pergunta vaga pois o juízo acerca do teatro só pode ser pronunciado após observar os seus efeitos sobre o povo para o qual as peças são escritas(ROUSSEAU, 1993: 40). Há, porém, grande diversidade de povos, de costumes, temperamentos e caracteres, e o espetáculo terá que ser julgado primeiramente em função do público a que se dirige. Aqui como em outros de seus escritos Rousseau exprime a contradição em que se encontra o homem consigo mesmo. Para Salinas (apud MATOS, O., 1994, p. 44) a raiz dessa contradição reside na vida em sociedade: "viver debaixo dos olhares é ser condenado inapelavelmente à não coincidência absoluta entre o interior e o exterior, entre o ser e o parecer." Pois o público é o homem "modificado pelas religiões, pelos governos, pelas leis, pelos costumes, pelos preconceitos e pelos climas" e que se tornou diferente de si mesmo. É o homem corrompido pela sociedade que encontramos no Contrato Social e no Emílio e que, antes disso era "uno" (ROUSSEAU, 1993, p. 40).

É desse modo que Rousseau se opõe, conforme Franklin Matos (ROUSSEAU, 1993, p. 11), ao etnocetrismo dos filósofos quando insiste na especificidade da tradição cultural de Genebra, opondo-se à proposição de D’Alembert, para o qual Genebra precisava de um teatro.

Em relação ao questionamento sobre qual a função social dos espetáculos em geral, e em particular a do teatro? considera-se que mesmo que D'Alembert e Rousseau discordem quanto ao tipo de espetáculo apropriado para a cidade, a verdade é que ele cumpre uma função social para ambos. Se para D'Alembert (1993, p. 153) o teatro proporciona o aperfeiçoamento do gosto e dos costumes dos homens e essas aquisições estão ligadas a uma consideração de ordem moral e política que é dirigida de maneira autoritária aos cidadãos, para Rousseau está implícita na idéia da festa a concepção segundo a qual esse povo se organiza de maneira própria, sem a direção de outra pessoa. Aí ele não é somente espectador, mas ator .

A crítica de Rousseau é abrangente: ele analisa as influências nocivas dos espetáculos e levanta dúvidas e questões dadas por resolvidas por D’Alembert, dentre as quais a que seria, talvez, a mais importante delas, a relação necessariamente benéfica entre progresso, entenda-se: sofisticação e popularização do entretenimento e das formas de arte, e bem-estar social.

\footnotetext{
${ }^{3}$ Cf. as obras dos enciclopedistas franceses, mas também de filósofos como David Hume, que tal como estes estava às voltas com a questão do gosto, e para quem o juízo acerca de uma obra de arte dependia do refinamento, produto de uma educação do gosto.

${ }^{4}$ Essa sua consideração está também presente em Emílio no qual afirma que a função da educação é formar o homem e não o cidadão e formar o homem significa para Rousseau educar segundo a natureza, permitindo a expressão do que é a criança, de detro para fora.
} 
Os montanheses de Neuchâtel, por exemplo, a quem Rousseau faz referência na Carta ${ }^{5}$ possuem a autonomia própria das pequenas comunidades que se acomodaram, de modo conveniente, a uma forma de vida rústica que, de certo modo, se afasta do refinamento danoso que ele encontra em Paris. Essas vilas camponesas são independentes, têm seu próprio comércio, seus princípios morais; os ofícios e artes que praticam e aprendem são os que lhes interessam diretamente. Não se interessavam assim, pelo que acontecia fora do seu distrito porque, como tenta mostrar Rousseau, possuíam uma estrutura política sólida o bastante para permitir tal afastamento.

Rousseau analisa o que poderia acontecer nessas comunidades com a presença do teatro ali. Enumera uma série de prejuízos que essa comunidade sofreria com a presença do teatro, pois para ele, o teatro é espetáculo próprio de uma cidade como Paris, "onde tudo se julga pelas aparências" (ROUSSEAU, 1993, p. 75).

O que se pode depreender das críticas de Rousseau ao teatro francês, da defesa que fez do modo dos genebrinos se organizarem cultural e politicamente, da defesa que faz da festa popular e ainda de que o próprio Rousseau tenha escrito inúmeras peças teatrais é que para Rousseau "a posição da cena no interior de cada cidade jamais é a mesma, que esta posição varia segundo o caráter, os costumes, o temperamento de cada povo, ou seja, de acordo com o tempo e o espaço" (MATOS, F., 1993, p. 11). Mas isso não significa a abolição completa do teatro (em síntese, da mímesis, como em Platão), mas o reconhecimento de que importa "o uso que se dá a essa proposição, como preparação de uma genealogia de valores: ela torna possível uma hierarquização das diferentes formas de espetáculo mediante um diagnóstico da qualidade do público" (MATOS, F., 1993, p. 11-12).

Para Rousseau, no entanto, não se trata, quando se identifica o gosto do público, de agradálo ou adulá-lo. Isso acontece quando o autor apresenta ao público um "quadro" de suas paixões "cujo original está em nossos corações" de maneira a "acompanhar o sentimento do público" (ROUSSEAU, 1993, p. 41).

Desse modo, o autor das tragédias também joga com esse sentimento ao ressaltar o que o público gosta e apresenta em cores detestáveis as odiadas naturalmente. Esse é o princípio da distração e do entreteimento. O público segue atentamente, porém de maneira distendida (distraída) aquilo que está acostumado a ver: ele na verdade aprecia a representação de si mesmo no palco, sem ter dessa imagem qualquer crítica.

A identificação das diferenças de Rousseau possui uma conotação positiva, pois indica as particularidades de um povo com sua originalidade, tornando-o único em suas características sociais. Essa identificação ela nos interessa aqui, pois marca a importância da concepção de povo e de popular em Rousseau, assim como essa concepção se distingue do público para o qual se dirigem os meios de comunicação.

Para Rousseau, saber diferenciar e respeitar as diferenças existentes entre os povos é preservar suas respectivas liberdades, é garantir que suas manifestações estéticas, políticas, morais, façam sentido porque nasceram de uma organização própria, contextualizada e determinada pela história particular da comunidade. As diferenças indicam a proximidade ou não com o estado de natureza, estado onde a autenticidade encontra seu lugar próprio, onde as expressões de um povo estão mais próximas da originalidade, e onde a particularidade encontra sua essência e seu significado.

\footnotetext{
${ }^{5}$ Lembro-me de ter visto, em minha juventude, nas cercanias de Neuchâtel, um espetáculo bastante agradável e talvez único na terra" (ROUSSEAU, 1993, p. 76). É significativo que Rousseau refira-se a essa paisagem - "uma montanha coberta de casas, cada uma das quais formando o centro das terras que a ela pertencem" - como a um espetáculo.
} 
Será interessante aqui nos referirmos ao modo como Rousseau ressalta na Carta, o meio pelo qual considera que é possível atuar sobre a opinião do povo e fazê-lo mudar de idéia. Pois se não é o teatro que pode fazer isso - o teatro é para ele um mero espelho dos costumes da cidade - pergunta ele "como pode então o governo agir sobre os costumes?" (ROUSSEAU, 1993, p. 81). O exemplo que dá é o do tribunal dos marechais da França, instituído para mudar a opinião pública sobre os duelos. Não vamos descrever aqui com detalhes o exemplo de Rousseau, mas apenas indicar que se trata de uma ação do governo que objetivou suprimir o costume de "tirar satisfações de uma afronta com a espada na mão" (ROUSSEAU, 1993, p. 82). A questão discutida por Rousseau é de uma forma indireta sua reflexão sobre o papel do teatro: este tem para ele a função de reproduzir o que o publico pensa e como age. Qualquer outra forma que vise mudar esse comportamento deve ter a mediação do governo. Assim, percebemos que para Rousseau, a relação com "os outros" é mediada pelo governo, por meio da opinião pública e não pelos meios de comunicação ou pelo teatro que é um dos lugares em que o público se encontra. O modo então de superar o isolamento não é o teatro, mas o chamado de um governo que levará a comunidade a se perceber como tal. Desse modo, a ação definida que promove, de alguma forma, a influência sobre a opinião pública pode ser vista como a forma que o teatro deve ter, segundo Rousseau.

Por outro lado, quando um povo preserva sua essência mediante, por exemplo, espetáculos que estejam de acordo com seus costumes, não corre o risco de se corromper, não macula seu gosto estético ou seus hábitos com as conveniências da sofisticação criadas pela sociedade, não sacrifica à opinião alheia modos de expressão que lhe são significativos e não desperdiça seu tempo com atividades vazias e inúteis. Esse espetáculo é para Rousseau a festa. Ela não acontece "num antro escuro" e que mantem o povo na inação, mas ao ar livre. Essa festa não precisa de palco e nem de atores, mas o próprio povo poderá sê-lo. "Plantai no meio de uma praça uma estaca coroada de flores, reuni o povo e tereis uma festa. Ou melhor ainda: oferecei os próprios espectadores como espetáculo; tornai eles mesmos atores" (ROUSSEAU, 1993, p. 128). A festa é, porém, o espetáculo dos "povos felizes" e não o modo de tornar o povo feliz ou consciente de sua unidade enquanto tal.

Rousseau não insiste nem no aspecto positivo e salutar do teatro, nem na possibilidade de o teatro modificar para pior os costumes dos cidadãos, pois o teatro não promoverá qualquer mudança. Aristóteles defende a forma trágica como aquela que propicia um aprendizado, na maior parte das vezes positivo, ao cidadão ateniense. Embora devamos respeitar Aristóteles, não é certo que cidadãos do século XVIII extraiam aprendizado da mimese da mesma forma que os atenienses da era clássica. Se, no entanto, Rousseau recusa a forma intermediária do drama burguês, considerando que as formas existentes no teatro francês são o que elas podem ser (MATOS, F., 1993, p. 210), ele o faz por considerar que a mimese tem suas limitações ao representar no palco os cidadãos melhores ou piores do que são. Essa recusa ainda impede Rousseau de ver no surgimento ou evolução dos gêneros a expressão do modo peculiar que têm os povos, de épocas e lugares diversos, de exprimir suas paixões. Tal evolução pode-se considerar como um movimento no sentido de adequar o teatro ao caráter, ao temperamento e aos costumes de um povo.

É na relação com tal processo de evolução, de transformação das formas de expressão que Benjamin considera positivamente os programas de difusão pelo rádio. Num pequeno texto intitulado Hörmodelle (Modelos auditivos), escrito em 1931, afirma que a intenção fundamental destes modelos auditivos é didática e que o objeto do ensinamento são as situações típicas do cotidiano. O método de ensinamento consiste na confrontação do exemplo com o contraexemplo.

\footnotetext{
6 "Como pode então o governo agir sobre os costumes? Respondo que através da opinião pública. Se na solidão nosso hábitos nascem de nossos próprios sentimentos, na sociedade eles nascem da opinião dos outros. Quando não se vive em si mesmo, mas nos outros, são os julgamentos deles que ordenam tudo" (ROUSSEAU, 1993, p. 81).
} 
O formato proposto por Benjamin para uma peça radiofônica prevê o seguinte: há sempre um apresentador que aparece três vezes: no início, no meio e no fim. E com, no máximo, mais três vozes. O apresentador introduz o ouvinte na temática que será tratada, apresenta ao público os interlocutores e ao final faz comentários, comparando as situações. No entanto suas peças nem sempre se adaptam a ele.

O que é importante para Benjamin é que o rádio se constitui num elemento revolucionário no que concerne à popularização. Esta tem sido tradicionalmente uma forma secundária, pois antes do surgimento do rádio não se conhecia um meio de difusão que correspondesse aos objetivos da popularização. As formas de comunicação não se distinguiam em nada das vias pelas quais a pesquisa científica conhece suas descobertas, pelos especialistas (BENJAMIN, 1980, IV, p. 672).

Graças às possibilidades técnicas do rádio - que são aquelas de se endereçar simultaneamente a um público ilimitado - a popularização ultrapassou seu caráter bem intencionado e filantrópico e se transformou em um exercício cuja forma e gêneros estão submetidos a leis específicas que se distinguem nitidamente do modo tradicional de popularização, que a publicidade moderna emancipou dos primeiros ensaios do século XIX.

Em Hörmodelle como em outros textos seus ${ }^{7}$ Benjamin externa seu otimismo em relação ao desenvolvimento técnico. Se no referido ensaio sobre a obra de arte, escrito alguns anos mais tarde, ele afirma que as técnicas vêm colocar a arte ao alcance das massas urbanas, além de proporcionar momentos de distensão, necessários ao cidadão da metrópole; aqui o rádio é visto de modo positivo, haja vista permitir um alcance maior do público. A popularização é para ele um evento importante no contexto da modernidade, pois ao mesmo tempo em que o desenvolvimento técnico está a serviço da expansão do desenvolvimento capitalista e se constitui numa forma de integrar as massas a um processo de aprendizado que não é necessariamente, como pensava Adorno, alienante, pois a massa quando se apodera desses meios, os absorve e adequa ao seu modo de utilização.

Benjamin compara nesses textos o método tradicional de popularização com essa novidade trazida pelos meios de comunicação. O método tradicional de popularização partia de dados científicos certos e comprovados e os apresentava tais como a ciência os havia elaborado, suprimindo as idéias difíceis ${ }^{8}$. Sua estrutura era de um manual com suas partes principais em caracteres normais, e as digressões em pequenos caracteres. O rádio, no entanto, propiciava para o crítico alemão outra forma de aproximação dos ouvintes com questões de cunho científico. A transmissão radiofônica deveria produzir um trabalho de formação, interessar o especialista, assim como o leigo.

É conhecido o termo semiformação de Adorno, que se refere à determinação social da formação na sociedade capitalista produtora de mercadorias. Na Dialética do Esclarecimento (ADORNO; HORKHEIMER, 1985) os autores denunciam a reificação e o fetichismo como resultado de um processo histórico de distanciamento do homem de si mesmo e das coisas, processo esse que resulta do uso instrumental da razão e produziu o pensamento que coisifica e aliena: seu ápice é o capitalismo industrial. Na sociedade industrializada a cultura se torna um produto colocado à disposição das massas para o consumo fácil e de rápida substituição. "A semiformação (Halbbildung) faz parte da reprodução da vida sob o monopólio da 'cultura de massas'”, termo que Adorno substitui por Indústria Cultural, pois este torna possível "apreender a tendência à determinação total da vida em todas as suas dimensões pela formação social capitalista” (MAAR, 2003, p. 460).

\footnotetext{
${ }^{7}$ Por exemplo, A obra de arte na era de sua reprodutibilidade técnica (cf. BENJAMIN, 1985, p. 165-196).

${ }^{8}$ Ou seja, procedia pela simplificação, tal como muitas vezes consideramos que um conteúdo de alto nível de complexidade deve ser transmitido a um público leigo. Um exemplo disso: aulas de filosofia para o ensino médio. Simplificar é somente, podemos dizer, comunicar; não produz aprendizado.
} 
Para Benjamin, no entanto, o que a sociedade produtora de mercadorias impõe sobre as coisas é a "forma mercadoria", não impingindo a elas um modo determinado de absorção e nem uma função determinada. Se antes a relação entre popularização e ciência era exterior, isto é, não havia um modo de difusão que penetrava a ciência e a transformava, essa relação foi substituída por um procedimento que a própria ciência não pode contornar. Trata-se, pois, de uma popularização que não mobiliza somente o saber na direção do público, mas este na direção do saber. Em uma palavra, o interesse realmente popular é ativo sempre. Ele transforma os dados científicos e age sobre a própria ciência.

Trata-se aqui de estabelecer, para Benjamin, a relação que tem agora o público com as obras artísticas ou com a ciência. A presença das massas nos grandes centros urbanos é que dá o tom dessa relação, pois o público não é para ele somente o destinatário de uma mensagem, mas aquele que engole a obra tal como absorve todas as coisas e se torna "matriz" (BENJAMIN, 1994, p. 192) de uma regeneração. Nesse ensaio Benjamin menciona a arquitetura como arte que sempre foi pública e faz apelo a todos os sentidos.

Por outro lado, o desenvolvimento técnico colocou à disposição das massas aparelhos (máquinas fotográficas, filmadoras) que mediante o seu uso transformam-nas de meras observadoras e espectadoras em produtoras, e também em personagens atuantes na definição dos destinos dessas mesmas técnicas. Mas, para Benjamin, o que depende do modo como essa personagem é colocada o palco da história, e do lugar que ela ocupa. Em A obra de arte na era de sua reprodutibilidade técnica ele discute o papel que têm as massas nas encenações nazistas: ali elas são somente público que assiste e aplaude. Porém não é somente esse o papel que elas podem representar.

Em suas peças radiofônicas ele nos indica o caminho possível para superar a contradição existente na cidade moderna, entre o jogo e norma, entre a estandardização dos estímulos e o jogo dos sinais que organizam o fluxo urbano.

Benjamin começou a trabalhar com peças radiofônicas e sua transmissão pelo rádio em 1929, pouco depois de ter conhecido Brecht. Sua colaboração com a Funkstunde de Berlim estende-se até a primavera de 1932, e com a Südwestdeutscher Rundfunk de Frankfurt, até janeiro de 1933. E todo esse período é marcado pela influência do teatro épico. Poucas dessas peças e conferências literárias foram publicadas em suas obras completas, como as conferências sobre Brecht, Kafka, as peças radiofônicas infantis e as Hörmodelle, modelos radiofônicos cuja forma é próxima das peças didáticas. Benjamin escreveu esses trabalhos com o objetivo de utilizar, de "forma inteligente" (LACOSTE, 2003, p. 195) esse novo meio de comunicação de massa "que transforma radicalmente a relação entre o autor e seu público" (LACOSTE, 2003, p. 196). Para que possamos compreender de que modo essa utilização foi pensada por ele, de modo a explorar as potendialidades dessa nova técnica, e compreendermos também sua idéia de popularização examinemos aspectos de uma de suas peças radiofônicas, O que os alemães liam enquanto seus clássicos escreviam. Trata-se nessa peça de uma conversa literária que se passa em fins do século XVIII (1795-1800).

A peça foi transmitida em 16/02/1932, com a qual Benjamin obteve não só um bom pagamento mas, também, sucesso. Como personagens, temos a voz do iluminismo, do romantismo e do século XIX em disputa com um locutor; tal voz gira em torno dos temas acerca da literatura e do mercado de livros daquela época. A ação se passa em um café berlinense e em uma livraria de Leipzig. As personagens exprimem suas características singulares por meio da fala e das atitudes e documentam o que "era naquela época milenar e em voga e que a tipificação permite: não a literatura, mas a

\footnotetext{
9 "A massa é a matriz da qual emana, no momento atual, toda uma atitude nova com relação à obra de arte" (BENJAMIN, 1994, p. 192).
} 
conversa sobre literatura" (BENJAMIN, 1980, IV, p. 673). A troca de opiniões, seja intelectual ou acidental, transforma-se em acesso metódico à situação histórica. Um corte temporal abrevia o final na direção da atualidade. A voz do século XIX diz: "Mas ao mesmo tempo, meu século deu ao espírito os meios de se expandir mais depressa do que pela leitura" (BENJAMIN, 1980, IV, p. 670). O locutor acrescenta: "e instaurou com isso a tirania do minuto", e o tic-tac do ponteiro dos segundos acompanha o decorrer do tempo da transmissão radiofônica (a idéia é a de sugerir ao espectador a sensação e não a de fazer um discurso sobre ela).

Benjamin experimenta aqui um total cruzamento de matéria e forma. Com a transmissão temática de uma "questão de conhecimento" da época, a forma se transpõe em modelo de peça. A didática recebe na peça uma sutil diferenciação: "para alcançar a profundidade partiu-se deliberadamente da superfície" (BENJAMIN, 1980, IV, p. 673). Portanto o comentário da conversa histórico literária não serviu, assim como os documentos históricos postais, nem a uma "ambição filológica nem a uma duvidosa necessidade de formação" (BENJAMIN, 1980, IV, p. 944), mas "à comunicação, que possibilita ainda o debate com os pequenos dentre seus contemporâneos." Não aparecem os grandes espíritos da Alemanha e nem se lê amostras de obras literárias. Com ela, o autor procurou apresentar ao ouvinte o que efetivamente existiu em profusão e à vontade, a tal ponto que o ouvinte pudesse identificar as vozes nos tipos presentes na conversação literária.

A conversação coloca à luz uma variedade infinita de escolas literárias e de jornais, a censura e as livrarias, a formação de jovens e as bibliotecas públicas, o iluminismo e o obscurantism, e isto nos cafés e nas feiras de livros, nas vendas em leilões ou durante os passeios. Tal conversa tem, ao mesmo tempo, uma relação mais estreita com as interrogações dos estudos literários mais avançados, que se esforçam mais e mais para pesquisar sobre as condições que a situação da época impunha à criação. É uma forma de transmitir ao público moderno uma situação que lhe corresponde como passado, permitindo a esse público estabelecer os nexos entre seu presente e esse passsado, que de alguma forma lhe diz respeito, para além do que os livros contam a história.

A nova popularidade é uma posição fundamental em relação aos meios de comunicação. Há muito tempo, "uma região precária da ciência" (BENJAMIN, 1980, IV, p. 527) a popularização não legitima-se através da mera simplificação, mas através de seu efeito pragmático: "libertar o saber do limite da especialidade e torná-lo prático" (IV, 559), é a tarefa de uma preparação de aproximação do público. 
OS EFEITOS DA MIMESE | Sônia Campaner Miguel Ferrari

\section{Referências}

ADORNO, T. W.; HORKHEIMER, M. Dialética do esclarecimento. Tradução Guido António de Almeida. Rio de janeiro: Jorge Zahar, 1985.

BENJAMIN, W. Gesammelte schriften. Frankfurt: Suhrkamp Verlag, 1980. v. I-IV.

Obras escolhidas: magia e técnica, arte e política. São Paulo: Brasiliense, 1994.

D'ALEMBERT. Verbete Genebra. In: ROUSSEAU, J.-J. Carta a D'Alambert. Tradução Roberto Leal Ferreira. Campinas: UNICAMP, 1993.

LACOSTE, J. L'aura et la rupture. Walter Benjamin, Paris, Maurice Nadeau: 2003.
MAAR, W. L. Adorno, semiformação e educação. Educação e Sociedade, Campinas, v. 24, n. 83, p. 459-476, 2003.

MATOS, F. de. Introdução: teatro e amor próprio. In: ROUSSEAU, J.-J. Carta a D'Alambert. Tradução Roberto Leal Ferreira. Campinas: UNICAMP, 1993.

MATOS, O. C. F. Rousseau, a festa e a política. Cultura Vozes, n. 3, p. 42-48, maio/junho 1994.

ROUSSEAU, J.-J. Carta a D'Alambert. Tradução Roberto Leal Ferreira. Campinas: UNICAMP, 1993. 